Luisa Herbst

\title{
Who Pays to Win Again? The Joy of Winning in Contest Experiments
}

Max Planck Institute for Tax Law and Public Finance

Working Paper 2016 - 06

April 2016

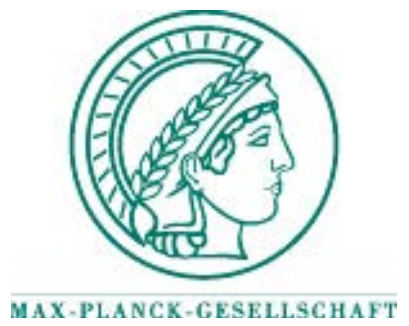

Max Planck Institute for Tax Law and Public Finance

Department of Business and Tax Law Department of Public Economics

http://www.tax.mpg.de 
Working papers of the Max Planck Institute for Tax Law and Public Finance Research Paper Series serve to disseminate the research results of work in progress prior to publication to encourage the exchange of ideas and academic debate. Inclusion of a paper in the Research Paper Series does not constitute publication and should not limit publication in any other venue. The preprints published by the Max Planck Institute for Tax Law and Public Finance represent the views of the respective author(s) and not of the Institute as a whole. Copyright remains with the author(s).

Max Planck Institute for Tax Law and Public Finance

Marstallplatz 1

D-80539 Munich

Tel: $\quad+498924246-0$

Fax: $\quad+498924246-501$

E-mail:ssrn@tax.mpg.de

http://www.tax.mpg.de 


\title{
Who pays to win again? The joy of winning in contest experiments*
}

\author{
Luisa Herbst $^{\dagger}$
}

April 15, 2016

\begin{abstract}
In contest experiments, overbidding is a widely observed phenomenon. One common explanation for overbidding is that winning in itself yields utility, termed the joy of winning. However, the joy of winning is difficult to observe and to quantify. This paper develops a novel, incentivized way to measure the individual-specific joy of winning as well as the frustration of losing in a Tullock lottery contest. We find that the willingness to pay for a restart of the contest differs between winners and losers. Compared to a theoretical benchmark, winners are more satisfied and overbid for restart of the contest, while losers are less satisfied and underbid. Further, effort levels are higher in the second contest, which can be explained by selection of high effort types with a high joy of winning into the restarted contest.
\end{abstract}

JEL codes: C78, C91, D72, D74

Keywords: Bidding, contest, desire to win, effort, experiment, emotions, joy of winning, love of winning, overexpenditure

\section{Introduction}

Redistributing resources by fighting a contest may in addition to allocative implications also have more subtle consequences for the contest participants: The winner of the contest may enjoy the pride and happiness of winning and being first, while the loser of the contest may suffer from his failure and be frustrated by having exerted effort in vain. This may be true for a variety of contests between individual decision-makers, be it promotion contests, sports contests or political contests. For some applications such as cardboard games,

${ }^{*}$ I thank Sabine Aresin, Helmut Bester, Roy Chen, Luis Corchón, Michael Hilmer, Marco Kleine, Kai Konrad, Jingfeng Lu, Ronnie Schöb, Roman Sheremeta, Fangfang Tan, participants of the EBCC in Brisbane (2016), of workshops in Munich (MPI) and Singapore (NUS), and my colleagues at the MPI for helpful comments. Moreover, I thank the econlab in Munich for providing laboratory resources. Financial support from the German Research Foundation (DFG, grant no. SFB-TR-15) is gratefully acknowledged.

${ }^{\dagger}$ Max Planck Institute for Tax Law and Public Finance. E-mail: luisa.herbst@tax.mpg.de. 
victory even comes without any allocative or monetary consequences. In these contests, especially if there is a lot of randomness in individual performance, non-monetary effects such as the so-called joy of winning seem to be a major motivation for why people strive to be first.

In the experimental economics literature, this joy of winning has been used to explain overexpenditure in lottery contests, compared to a theoretical benchmark. ${ }^{1}$ The intuition is that players value the prize higher than its pure monetary value, in other words, they derive additional utility from the fact that they have won. If the extent of the additional utility differs across individuals, the joy of winning can not only explain the overexpenditure, but also the heterogeneity in contest efforts observed. Due to its explanatory power, the existence of a joy of winning is increasingly accepted in the literature discussing experimental contests (e.g., Brookins and Ryvkin 2014, Cason et al. 2013, Hart et al. 2015, Herbst et al. 2015, Mago et al. 2013, Morgan et al. forthcoming, Price and Sheremeta 2011 and 2015). The acceptance is also reflected by the fact that more and more theory models on lottery contests include it. ${ }^{2}$ Nevertheless, there is little undisputed empirical evidence for such a joy of winning in experimental contests. The lack of strong empirical evidence is the main motivation for this paper.

The most prominent test for an inherent joy of winning in experimental contests has been developed by Sheremeta (2010): After the main part of a contest experiment, players can invest effort in another contest, in which the prize value is set to zero. That is, the players are actually fighting for nothing. The effort expended in this zero-prize-contest is then taken as a measure for the joy of winning. This post-test has been implemented by a number of recent contest experiments (e.g., Brookins and Ryvkin 2014, Cason et al. 2013, Herbst et al. 2015, Mago et al. 2013, Price and Sheremeta 2011 and 2015). Yet, some open questions remain: Are some players just too tired and fatigued at the end of the experiment that they do not pay full attention to the experimental task? Are their effort choices in a zero-prize-contest therefore merely a repetition of previous effort choices? Thus, the reliability of this measure is questionable. Moreover, the effort in a zero-prize-contest is a one-sided measure in that it cannot yield any insights on the frustration of losing. Without further controls, it is also impossible to disentangle the joy of winning from the joy of playing a lottery.

The contribution of this paper is twofold. First, we introduce an alternative experimental way to measure the joy of winning. Second, we also measure the frustration of losing, which allows us to test for asymmetries between being ahead and behind. We test for both of these non-monetary utility effects in two different ways, one incentivized and one non-incentivized. For the incentivized

\footnotetext{
${ }^{1}$ A variety of explanations exist for why people overexpend effort. Sheremeta (2015) tests a number of different reasons for this phenomenon, with the joy of winning being one of them.

${ }^{2}$ See for example Kräkel (2008). More recently, Cotton et al. (2015) and Metzger (2015) model players with heterogeneous values of winning a prize, referring to the joy of winning. Gauriot and Page (2016) also include the utility of winning in their model to rationalize empirical data from tennis matches.
} 
part, two players first take part in a Tullock lottery contest. Once they know their realized payoffs, they can place a (negative or positive) bid for playing again. The model framework yields a prediction for this bid for playing again, against which we can compare the observed bid. With this comparison, we can test for over- or underbidding as regards playing the contest again. Additionally, we can differentiate between players that have won or lost prior to the decision on bidding for a restart. For the non-incentivized part, the players are asked about their current satisfaction level with respect to their experience in the experiment right before and right after the contest. This is in line with the usual practice of using self-reported emotional states which has recently been introduced into experimental economics and which is a proxy for player's utility. ${ }^{3}$ An additional contribution is that we dive further into some different dimensions of the joy of winning and the frustration of losing. More specifically, we test whether the joy of winning and the frustration of losing depend on the outcome being expected or unexpected and on the outcome seeming to be narrow or clear.

The results show that compared to the prediction, winners bid too much for a restart of the contest and losers bid too little, indicating a joy of winning for winners and a frustration of losing for losers. Emotionally, winners report to be more satisfied than losers, although the difference can also be explained by monetary payoffs. Both measures of the joy of winning, overbidding and the change in satisfaction, are significantly positively correlated, but they are uncorrelated with the effort players expend in a zero-prize contest (Sheremeta, 2010). Furthermore, effort levels in the repeated contest are higher. This alludes to both selection and behavioral effects: The restarted contests attracts high effort types and induces stronger competition.

This paper is related to different strands of the literature. First and foremost, Sheremeta (2010) developed a direct test for the joy of winning in experimental contests as discussed above. Yet, the joy of winning has also been under investigation in other contexts. With a psychometric approach, i.e. analyzing data from extensive questionnaires, Franken and Brown (1995) analyze how the importance of winning differs between different individuals. Ding et al. (2005) study how the joy of winning influences bids in internet auctions. Malhotra (2010) also uses bids in online auctions to study competitive arousal from a decision-making aspect, which is also the focus of a paper by Malhotra et al. (2008). Coffey and Maloney (2010) study the "thrill of victory" with data from dog and horse races and Matsumoto and Willingham (2006) study the thrill of victory with photos of facial expressions from judo competition winners. Unlike these papers, we are interested in the joy of winning in the experimental laboratory. The laboratory also provides a controlled environment and the possibility to incentivize individual decisions from which we deduce the joy of winning and the frustration of losing.

The consequences of winning and of losing are the focus of some other papers: Bühren and Pleßner (2014) show that winners are more likely to pay for

\footnotetext{
${ }^{3}$ Lang and Morath (2015) recently used it in their experiment and Perez-Truglia (2015) provides a validation test of using stated subjective well-being data.
} 
actually getting a physical trophy, Kidd et al. (2013) find that winning increases generosity, especially if winning comes unexpectedly, Kasumovic and Kuznekoff (2015) show that losers of a video game make more negative and more sexist comments, Buser (forthcoming) shows that following a loss, players set a higher performance target for themselves, while Johnson and Salmon (2016) show that low ability subjects get discouraged from not being promoted if promotion decisions are unrelated to ability. We also look at the consequences of winning or losing, with a special interest on the player's willingness to play the contest once more. This yields a simple measure for the joy of winning and the frustration of losing at the same time.

One of the first papers to study emotions in the laboratory more generally is by Mellers et al. (1997). They use self-reported emotional states to point at the emotional aspect of decision making. Brandts et al. (2009) study the impact of rivalrous situations on subjective well-being in general and more specifically on happiness and joy (among other emotions). They find that joy is positively correlated with success in a two-player social dilemma interaction. Adam and a number of coauthors (Adam et al. 2011a, 2011b) have measured emotions using physiological measures and psychometric scales. Using skin conductance rates, Astor et al. (2013) and Adam et al. (2015) find that depending on the specific type of auction, the joy of winning can be smaller or larger than the frustration of losing. Using functional Magnetic Resonance Imaging techniques, Dohmen et al. (2011a) show that solving a task that a comparison subject has not solved positively affects reward-related brain areas. Haran and Ritov (2014) find that the self-reported anticipated sadness of losing more strongly influences bids in a first-price sealed-bid auction than the self-reported anticipated happiness of winning does. Bosman et al. (2014) also use self-reported emotions and find that winners of a random lottery experience more positive emotions and positive surprise than losers, with positive consequences on option price estimates. While it is informative to analyze the joy of winning under all kinds of rivalrous conditions, auction and contest types, we choose the Tullock lottery contest as our focus of interest, also following the literature that begins with Sheremeta (2010).

In the next Section we introduce the model framework, line out the experimental design and explain our hypotheses. We analyze and discuss the empirical data in Section 3 and provide concluding remarks in Section 4.

\section{Framework}

\subsection{Theory background}

There are two players $A$ and $B$ that fight for a prize of monetary value $V$ in a Tullock lottery contest. In a first stage, both players simultaneously choose effort $x_{i}, i=A, B$, which influences their winning probability. The unit cost

of effort is assumed to be constant and equal to one. Player $i$ 's probability of winning the prize is equal to 


$$
p_{i}\left(x_{A}, x_{B}\right)=\frac{x_{i}}{x_{A}+x_{B}}, \quad i=A, B
$$

if $x_{A}+x_{B}>0$ and equal to $1 / 2$ otherwise. Player $i$ 's expected payoff is

$$
E \pi_{i}\left(x_{i}\right)=p_{i}\left(x_{A}, x_{B}\right) V-x_{i}, \quad i=A, B,
$$

that is, $i$ 's expected payoff is equal to his probability of winning multiplied by the prize, minus the effort cost.

Player $i$ maximizes his expected payoff $E \pi_{i}$ and invests $x_{i}^{*}=\frac{V}{4}$ in equilibrium. This yields an equilibrium expected payoff of $E \pi_{i}^{*}=\frac{V}{4}$. By construction, there will be a winner and a loser in this contest. Realized ex post payoffs are $\pi_{W}=V-x_{W}$ for the winner and $\pi_{L}=-x_{L}$ for the loser, where $x_{W}$ and $x_{L}$ describe the effort exerted by the winner and loser, respectively.

Once the realized payoffs are known, players can bid $b_{i} \in[-V, V], i=A, B$, for a restart of the contest in a second stage. If the sum of these bids, $b_{A}+b_{B}$, is positive, the game is restarted. A restart means that the payoff from the former contest is cancelled and instead the payoff from the new contest will be relevant for payment. Otherwise, if $b_{A}+b_{B} \leqslant 0$, the payoff from the former contest is relevant for payment and the players do not enter into the second contest. In our setup, inspired by the Vickrey Clarke Groves mechanism, only the pivotal player actually pays a bid to the laboratory and the absolute value of this bid is determined by the second-highest bid. The final payment $\Pi$ that players earn in the contest stage will thus be either the payoff from the new contest minus a positive bid for a restart (i.e. plus the the negative bid of the other non-pivotal player) if the player was pivotal in the decision for a restart (case 1 below), the payoff from the new contest (case 2 below), the payoff from the old contest (case 3 below) or the payoff from the old contest minus a negative bid for a restart (i.e. plus the positive bid of the other non-pivotal player) if the player was pivotal in the decision against a restart (case 4 below). Formally, final earnings $\Pi_{i}$ will be

$$
\Pi_{i}= \begin{cases}\pi_{i, \text { new }}+b_{-i} & \text { if } b_{i}>0 \wedge b_{-i} \leqslant 0 \wedge b_{i}+b_{-i}>0 \\ \pi_{i, \text { new }} & \text { if }\left(b_{i}>0 \wedge b_{-i}>0\right) \vee\left(b_{i} \leqslant 0 \wedge b_{-i}>0 \wedge b_{i}+b_{-i}>0\right) \\ \pi_{i, \text { old }} & \text { if }\left(b_{i}>0 \wedge b_{-i} \leqslant 0 \wedge b_{i}+b_{-i} \leqslant 0\right) \vee\left(b_{i} \leqslant 0 \wedge b_{-i} \leqslant 0\right) \\ \pi_{i, \text { old }}+b_{-i} & \text { if } b_{i} \leqslant 0 \wedge b_{-i}>0 \wedge b_{i}+b_{-i} \leqslant 0\end{cases}
$$

Given this setup, the players who value a restart positively (losers) have no incentive to understate their willingness to pay, but may have an incentive to overstate their willingness to pay. ${ }^{4}$ The players who value a restart negatively value (winners), on the other hand, might have an incentive to understate their

\footnotetext{
${ }^{4}$ As an illustration take a loser who has invested $x_{L}=150$ in the first contest (corresponding to a payoff of $\pi_{L}=-150$ ), which he takes into account when deciding on his bid, and expects
} 
willingness to pay, but never have an incentive to overstate their willingness to pay. ${ }^{5}$

Here, we concentrate on the equilibrium in weakly dominant strategies in which both players state their true willingness to pay. Thus, both players bid their true value of a restart, i.e.

$$
b_{i}=E \pi_{i, \text { new }}-\pi_{i, \text { old }}
$$

that is, players bid the expected payoff from the restarted contest, $E \pi_{i, n e w}$, minus the payoff from the old contest that will be cancelled if the second contest is played, $\pi_{i, \text { old }}$. Therefore, in equilibrium we have $b_{W}=-\frac{V}{2}$ for the winner and $b_{L}=\frac{V}{2}$ for the loser. Hence, the sum of both bids is zero in this sharp equilibrium prediction and the contest is never restarted.

\subsection{Experimental procedures}

The experiment was programmed using z-Tree (Fischbacher 2007) and run at the econlab laboratory in Munich, Germany. Subjects were recruited from the student body of Munich universities using ORSEE (Greiner 2004). We admitted 8 subjects to each session (104 participants in total), giving us 26 independent observations (4 subjects per matchinggroup). Subjects were on average 26 years old, a quarter of them studied an economics-related subject and $53 \%$ were male.

At the beginning of each session, written instructions were distributed and read out loud (see Appendix A.5 for a translation of the instructions). To make sure that subjects understood the experiment, they had to complete a quiz. This quiz included multiple-choice questions on the tasks described in the instructions and the payoff consequences of different decisions. When the experiment started, subjects had to count the number of zeros in five rows of 15 -digit number strings composed of "0"s and " 1 "s. ${ }^{6}$ Upon successful completion of a series of these (which was guaranteed by immediate feedback and the chance to correct a mistake in case it occurred), subjects received 750 tokens

$E \pi_{n e w}=125$. His true value for a restart is thus $b_{i}=275$. If he expects the other player to say $b_{-i}=-275$, then stating $\hat{b}_{i}=276$ instead of $b_{i}=275$ increases his expected earnings from -150 (payoff from the old contest) to 0 (payoff from the new contest minus bid minus payoff from old contest, $125-275+150=0$ ). That is, losers may have an incentive to overstate. Stating $\hat{b}_{i}=274$ does not change expected earnings if the player expects the other player to say $b_{-i}=-275$. If he expects the other player to say $b_{-i}=-274$, then stating $\hat{b}_{i}=274$ decreases expected earnings from $1(125-274+150)$ to -150 . Stating $\hat{b}_{i}=276$ does not change expected earnings if the player expects the other player to say $b_{-i}=-274$.

${ }^{5}$ As an illustration take a winner who has invested $x_{W}=150$ in the first contest (corresponding to a payoff of $\pi_{W}=350$ ), which he takes into account when deciding on his bid, and expects $E \pi_{n e w}=125$. His true value for a restart is thus $b_{i}=-225$. If he expects the other player to say $b_{-i}=225$, then stating $\hat{b}_{i}=-226$ instead of $b_{i}=-225$ increases expected earnings from 350 (payoff from the old contest) to 575 (payoff from the old contest minus bid, $350-(-225)=575)$. That is, winners may have an incentive to understate. Stating $\hat{b}_{i}=-224$ decreases expected earnings from 350 to -225 (payoff from the new contest minus payoff from the old contest, $125-350=-225)$.

${ }^{6}$ A similar task of counting zeros has been used by Kleine et al. (2016), and we are grateful for access to their experimental program. 
(which corresponded to 15 euros) for this task. These tokens served as their endowment for the subsequent parts of the experiment. This real effort task was implemented to avoid a house money effect.

In order for subjects to get familiarized with the contest environment, there were four rounds of the contest against a computer-animated player. The rules of this first stage of the contest were as described above with the prize value being equal to $V=500$ tokens. The subjects' maximum effort choices were restricted to $x^{\max }=\frac{V}{2}$, which is twice the equilibrium prediction and thus sufficiently far from a binding restriction. ${ }^{7}$ Both players chose their effort as a non-negative integer. The computer's effort choices and their order were pre-selected by the experimenter and replicated typical effort choices of human contestants in an experimental two-player Tullock lottery contest, i.e. there was some over-spending (on average $25 \%$ higher than the equilibrium prediction) and a tendency towards focal numbers (going for multiples of 25). The resulting win probabilities were illustrated in a circular area on the screen, with a pointer running clockwise determining the winner (compare the screenshot in Appendix A.1). Once the arrow had stopped, the subjects learned their payoff from this contest. The rounds against the computer provided ample learning opportunities for the subjects, with more than $90 \%$ of subjects experiencing both victory and loss in these rounds, although these rounds were not paid out and therefore involved no monetary consequences. Note that if the joy of winning is a phenomenon that disappears with learning, these four first rounds make it more difficult for us to find an effect.

Before the subjects entered into the contest against a human contestant, they had to answer "how happy or satisfied they are at the moment" (that is the translation of the exact wording in the experiment), on a scale from 0 to 10. For the contest, the subjects were randomly and anonymously matched in groups of two, with everything else equal to the contest rounds against the computer. Once subjects learned the outcome of the contest and the round was finished, the next screen reminded players of their contest payoff and of the fact whether they had won or lost. They were then again asked about their current satisfaction. $^{8}$ By comparing this answer to the self-reported level of satisfaction before the contest, we have a direct measure for the effect of winning or losing.

Afterwards, a new part started whose details were only announced to the subjects after they finished the first contest against a human contestant. In this part, the subjects could place a (positive or negative) bid for eliminating the result from the first contest and playing another contest round. Apart from the new matching, the setup of the restarted contest was exactly as the former contest, also including the question on current satisfaction after learning the outcome of the restarted contest. We did not want the subjects to base their bidding decision on social preferences towards their specific co-player in the

\footnotetext{
${ }^{7}$ Admittedly, in the experiment about $15 \%$ of the observed effort choices are at this limit. However, restricting effort choices was necessary to avoid possibe overall losses of subjects in the experiment.

${ }^{8}$ The screen said: "You have just (not) won the 500 tokens. Your payoff is xxx tokens. How happy or satisfied are you at the moment?"
} 
former contest, therefore, two players were again matched at random. Yet, we made sure to match a winner with a loser, although this feature was unknown to the subjects. A bid for a restart had to be a positive or negative integer between $-V$ and $V$. If the sum of both players' bids was positive, a new contest was played. Otherwise, if the sum of both players' bids was non-positive, the players moved directly on to the post-tests. In any case, only the pivotal player needed to pay a bid (i.e. he was to receive money if he placed a negative bid and was pivotal) and this was explained to the subjects in great detail and with a number of examples. ${ }^{9}$

Subsequently, the subjects underwent a number of incentivized tests. First, we elicited their preferences for playing a lottery (which was similar to the contest, but subjects had to decide whether to invest a fixed amount of tokens at a given win probability), then their distributional preferences (subjects had to repeatedly make two-person allocation decisions, following Bartling et al. 2009 and Balafoutas et al. 2012), effort in Sheremeta's zero-prize contest (which is widely used as a measure for the joy of winning) and their ambiguity aversion. Moreover, in the questionnaire the subjects were asked about their risk aversion (see Dohmen et al. 2011b), optimism, pessimism, loss aversion, experience in cardboard games and other competitions and a number of socioeconomic characteristics.

At the end of the experiment the subjects were paid separately and in private. The conversion rate was 50 tokens $=1$ euro. Each participant received a show-up fee of 6 euros, the earnings (possibly negative) of the first or second contest against another human player (including bidding) and the payoff (also possibly negative) from one randomly selected post-experimental task. On average, subjects earned 25 euros (excluding the show-up fee), and a session took about one hour.

\subsection{Hypotheses}

In equilibrium the expected contest payoff is $E \pi_{i}^{*}=\frac{V}{4}$. Rearranging the value of a restart (1), we get $E \pi_{i, \text { new }}=b_{i}+\pi_{i, \text { old }}$, i.e. the expected payoff from a new contest should be equal to the bid for playing this contest plus the payoff from the old contest, where the latter two can both be observed in the experiment. Taking the two expressions for the expected payoff together, we have $b_{i}+\pi_{i, \text { old }}-\frac{V}{4}=0$. If players value playing the contest a second time higher than its monetary value, this expression will not be equal to zero, in other words $E \pi_{i, \text { new }} \neq E \pi_{i}^{*}$, but $E \pi_{i, \text { new }}=E \pi_{i}^{*}+\Delta_{i}$. Hence, the difference $\Delta_{i}$ (our measure of interest) is given by

$$
\Delta_{i}=b_{i}+\pi_{i, \text { old }}-\frac{V}{4} .
$$

Even if the players expect to enjoy a joy of winning with some probability in the restarted contest, there should be no difference between winners and

\footnotetext{
${ }^{9}$ See the survey by Chen and Ledyard (2006) on how well different mechanisms to elicit the willingness to pay perform in the laboratory and Fukuda et al. (2013) for a more recent experiment using the Vickrey Clarke Groves mechanism.
} 
losers. However, if the joy of winning (and equivalently, the frustration of losing) persist for whatever reason even after the monetary payoff from this contest is eliminated, then only winners include a joy of winning in their expected payoff of a future contest and losers include a frustration of losing in their expected payoff of a future contest. ${ }^{10}$ According to this interpretation, we expect that the term $\Delta_{i}$ is positive for winners of the first contest and that $\Delta_{i}$ is negative for losers of the first contest. Independent of winning or losing, a possible (persistent) joy of playing the lottery would increase $\Delta_{i}$. Hence, the number $\Delta_{i}$ that we find is an upper bound for the joy of winning and a lower bound for the frustration of losing. However, such a joy of playing the lottery cannot explain a difference in the measure $\Delta_{i}$ between winners and losers.

Note that overbidding for playing again should not be confused with overexpenditure in the contest. Taking overexpenditure into account, the expected payoff from the restarted contest as well as the payoff from the old contest will be lower. ${ }^{11}$ The latter is accounted for individually as this payoff is observed. The former cannot be observed directly, but it would work against a joy of winning, with a lower expected payoff from a restarted contest decreasing rather than increasing the bids for replay.

Let us now turn our attention to the non-incentivized measure. We expect to see an increase in satisfaction after winning the contest and a decrease in satisfaction after losing the contest. These measures can also be used to test whether the magnitude of the effect on satisfaction is larger for winners or for losers.

Alongside the basic hypotheses on overbidding and increased satisfaction and the general measurement of the joy of winning, a special feature of the design allows us to test another hypothesis. Winning probabilities were illustrated by means of a fortune wheel with an arrow spinning clockwise on the screen. Hence, we have (visually) bare winners and losers versus sure winners and losers, depending on whether the arrow stopped close to the frontier between both players' winning regions or far away (compare the screenshots in Appendix A.1). We expect that the joy of winning and the frustration of losing are intensified if the victory or the loss seemed to be a tight one.

Another angle is to look at really sure or tight outcomes, depending on the probabilities of winning. Although the theory predicts no difference in these, Mellers et al. (1997) and Kidd et al. (2013) show that surprise enhances emotional reactions. Hence, it is informative to test whether the joy of winning is higher the lower the actual win probability of this player.

\footnotetext{
${ }^{10} \mathrm{~A}$ similar prediction arises if there are biases in evaluating probabilities and winners scale up their probability of winning and losers scale down their probability of winning.

${ }^{11}$ This also has consequences for the sum of both players' bids. The sum of bids is expected to be positive if there is overexpenditure in the first contest only and negative if overexpenditure is expected in the restarted contest only. The sum of bids will again equal zero if overexpenditure is of the same extent in both contests and symmetric for both players.
} 


\begin{tabular}{lccc}
\hline \hline & & & \\
& Winner & Loser & p-value \\
Bid $b_{i}$ & -50.6 & 55.7 & 0.002 \\
Bid difference $\Delta_{i}$ & $(14.9)$ & $(11.0)$ & \\
Change in satisfaction $\Delta s_{i}$ & 145.6 & -190.1 & 0.002 \\
& $(17.4)$ & $(12.4)$ & \\
& 1.25 & -1.13 & 0.003 \\
& $(0.17)$ & $(0.38)$ & \\
\hline \hline
\end{tabular}

Table 1: Bids, bid differences and change in satisfaction.

Note: Separately for winners and losers. Standard errors in parentheses, grouped at the matching group level. P-values for testing whether differences between winners and losers are zero.

\section{Results}

\subsection{Non-parametric analysis}

We begin the analysis by comparing the bids that winners and losers place for playing the contest a second time. Irrespective of the expected payoff from the new contest, winners give up a gain whilst losers forego a loss when the payoff from the old contest is eliminated. Thus, if the players in the experiment have a correct understanding of their incentives, bids by winners should be lower than bids by losers. Table 1 shows that on average winners bid $b_{W}=-50.6$ and losers bid $b_{L}=55.7$. (For comparison purposes, average expected bids are $E b_{W}=-196.2$ and $E b_{L}=245.8$.) As predicted, there is a significant difference between the two groups (p-value $<0.01$, Wilcoxon signed rank test at the matchinggroup level). The histogram of the bids (in Appendix A.2) shows that bids of winners are left-skewed and those of losers right-skewed. It also illustrates that more than $35 \%$ of the bids fall in the narrow range from -10 to 10. Despite the fact that the sum of bids does not significantly differ from zero, $46 \%$ of the subjects moved on to a restart of the contest.

The focus of this paper is to measure both, the joy of winning by the extent that winners overbid, and the frustration of losing by the extent that losers underbid. Therefore, we will now compare the observed bids with the theoretical prediction, taking into account individual payoffs from the first contest. Does the measure $\Delta_{i}=b_{i}+\pi_{i, \text { old }}-\frac{V}{4}$, which measures the difference of the observed bids to the expected value of a restart of the contest, differ between winners and losers? Table 1 presents evidence on a clear and significant difference between the joy of winning $\Delta_{W}=145.6$ and the frustration of losing $\Delta_{L}=-190.1$ (pvalue $<0.01$, tested at the matchinggroup level). Winners' bids are less negative than the predicted negative bids and losers bid a lower positive value than the 
predicted positive bids. The differences are in line with our hypothesis that winning is valued more highly than the prize itself and that losing comes with some depression. The differences cannot be explained by strategic incentives of the bidding mechanism, as winners may have an incentive to underbid, but not to overbid, and losers may have an incentive to overbid, but not to underbid, as explained above. Comparing the magnitude of both effects we find that the frustration of losing is larger than the joy of winning ( $\mathrm{p}$-value $=0.09)$ in line with findings from experiments on loss aversion according to which a loss is more painful than an equivalent gain is pleasurable and the general insight that bad is stronger than good (Baumeister et al. 2001). ${ }^{12}$

Result 1 After winning a contest, players bid more than the expected value of a restart for playing the contest again. After losing a contest, players bid less than the expected value of a restart for playing the contest again.

The scatterplot (in Appendix A.3) depicts the dispersion of bids across the bid-effort-space. We find a clear dichotomy between winners and losers. There is only a very low number of subjects who underbid upon winning and overbid upon losing ( 5 subjects in total). The incentivized measure suggests that the joy of winning as well as the frustration of losing exist and that they vary across subjects and across effort levels. ${ }^{13}$

Now let us consider the satisfaction measure for the joy of winning. As a first plausibility check of the data, we compare the satisfaction of winners and losers after the first real contest. We find that on a scale from 0 to 10 , winners on average report a level of $s_{W}=7.85$ and losers on average report a level of $s_{L}=5.23$, which is significantly lower (p-value $<0.01$, tested at the matchinggroup level). In principle, being inclined to be a winner and being in a generally happier mood could be systematically correlated. Thus, a cleaner test for the effect of winning or losing on satisfaction can be obtained by looking at the change in satisfaction that is induced by the contest. Table 1 shows that the affective reaction, i.e. the change in satisfaction $\Delta s_{i}$, is positive for winners and negative for losers, reinforcing the result on the incentivized measure for the joy of winning. The magnitude of the difference in satisfaction is basically the same for winners and losers $(\mathrm{p}$-value $=0.94)$.

Result 2 The self-reported satisfaction of players who won a contest significantly increases, whereas the self-reported satisfaction of players who lost a contest significantly decreases.

Remember that we also asked the subjects who replayed the contest for their current satisfaction after playing the second contest. Here, the reactions

\footnotetext{
12 Note that the difference cannot be explained by a joy of playing the lottery because such a joy increases both numbers.

${ }^{13}$ One way to understand the heterogeneity is to look at correlation coefficients between bid differences and individual-specific characteristics. Most of the characteristics we observe are not robustly correlated with the joy of winning measure. However, we find that envious subjects (deduced from two-person allocation decisions) have a significantly higher joy of winning or frustration of losing.
} 


\begin{tabular}{lcc}
\hline \hline & \multicolumn{2}{c}{ Restarted contest outcome: } \\
& & \\
Change in satisfaction $\Delta s_{2 i}$ & Winner & Loser \\
Winner in former contest & 0.42 & -5.11 \\
Loser in former contest & $(0.40)$ & $(1.15)$ \\
& 3.61 & -0.61 \\
& $(1.13)$ & $(0.53)$ \\
\hline \hline
\end{tabular}

Table 2: Average change in satisfaction induced by the restarted contest.

Note: Separated for winners and losers of the first and second contest. Standard errors in parentheses, grouped at the matching group level.

to winning or losing are even more pronounced with the change induced by winning the second contest being equal to $\Delta s_{W}=1.41$ and the change induced by losing the second contest being equal to $\Delta s_{L}=-2.85$. Table 2 includes an analysis on a more detailed level, separating these effects according to whether the player had been a winner or a loser in the former contest, i.e. whether the player's eliminated payoff was positive or negative. As before, the change in satisfaction is more positive if players end up being a winner in the new contest (for both rows, $\mathrm{p}$-value $=0.07$ for testing column differences). The affective reaction depends very much on the outcome of the former contest of which the payoff is eliminated: Independent of being a winner or a loser now, the change in satisfaction is more positive if the player had been a loser in the former contest (for both columns, $\mathrm{p}$-value $=0.07$ for testing row differences).

Comparing all four cases, we observe an intuitive ordering. Playing the second contest yields the largest increase in happiness for players who have lost before and win now $\left(\Delta s_{2, L W}=3.61\right)$, the reaction for players who win twice $\left(\Delta s_{2, W W}=0.42\right)$ is somewhat smaller, the reaction for players who lose twice is negative and small $\left(\Delta s_{2, L L}=-0.61\right.$, which is not significantly different from the effect of winning two times in a row) and the happiness of players who have won before and lose now strongly decreases $\left(\Delta s_{2, W L}=-5.11\right.$, which is more than half the available scale).

In line with our prediction, satisfaction of winners increases and satisfaction of losers decreases. Now let us check whether the intuition that the effects are larger if the outcome is a visually tight one holds true. In figure 1 we have separated the observations according to tight victories and losses on the one hand and sure victories and losses on the other hand. We classify an outcome as tight if the arrow on the fortune wheel determining the winner stopped within 18 degrees (i.e. $5 \%$ of the complete circle) towards the next border, and as a 
a) Bid difference $\Delta$

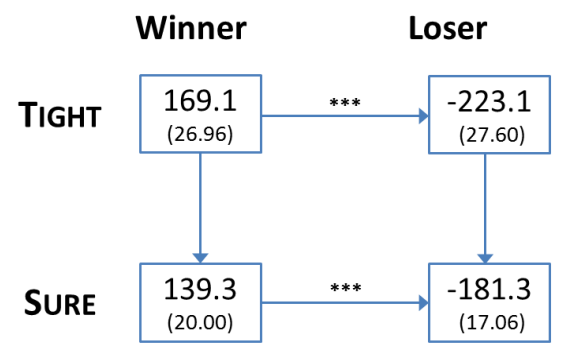

b) Change in satisfaction $\Delta s$

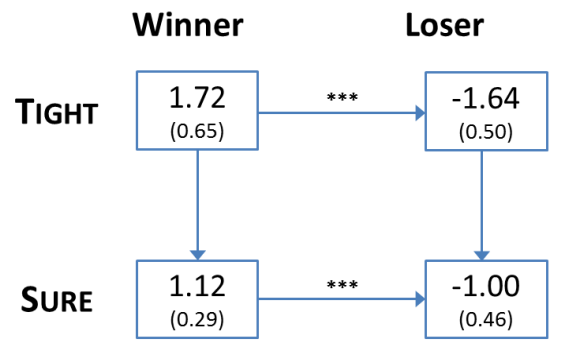

Figure 1: Bid difference (in panel a) and change in satisfaction (in panel b) for winners and losers, separated for tight victories (and losses) and sure victories (and losses).

Note: Standard errors in parentheses. 22 outcomes are classified as tight and 82 as sure.

sure outcome if the arrow stopped further away from the next border. ${ }^{14}$ The left panel depicts the bid differences, which are positive for winners and negative for losers. Interestingly, the absolute value of this measure for the joy of winning and the frustration of losing is larger for tight outcomes (upper row) than for sure outcomes (lower row). The right panel depicts the change in satisfaction that is induced by the contest. Winner's satisfaction increases, while loser's satisfaction decreases, and in line with our intuition, the size of both of these effects if stronger for narrow outcomes than for what seemed to be sure outcomes. Our prediction that visually tight outcomes lead to stronger reactions is qualitatively confirmed for both joy of winning measures (bid difference and satisfaction), yet we can only find statistical support for this statement for the case of testing bid differences ( $\mathrm{p}$-value $=0.08$, Mann Whitney $\mathrm{U}$ tests at the individual level on absolute values of bid differences, for winners and losers jointly).

Result 3 If the arrow on the fortune wheel stops in close proximity to the border between both players' winning regions, differences of observed bids to predicted bids are significantly higher and changes in satisfaction are higher than in the case in which the arrow stops far away from such a border.

Similar to the enhanced reaction when the arrow stops near the border between both winning regions, we expect that over- and underbidding as well as

\footnotetext{
${ }^{14}$ We get qualitatively the same results if the border is set to $20 \%$ (72 degrees) or at the median of the observations, except for the fact that in the latter case, the satisfaction increase for winners for which the arrow stopped closer to the border (1.1) is not larger than the satisfaction increase for winners for which the arrow stopped further away from the border (1.4).
} 


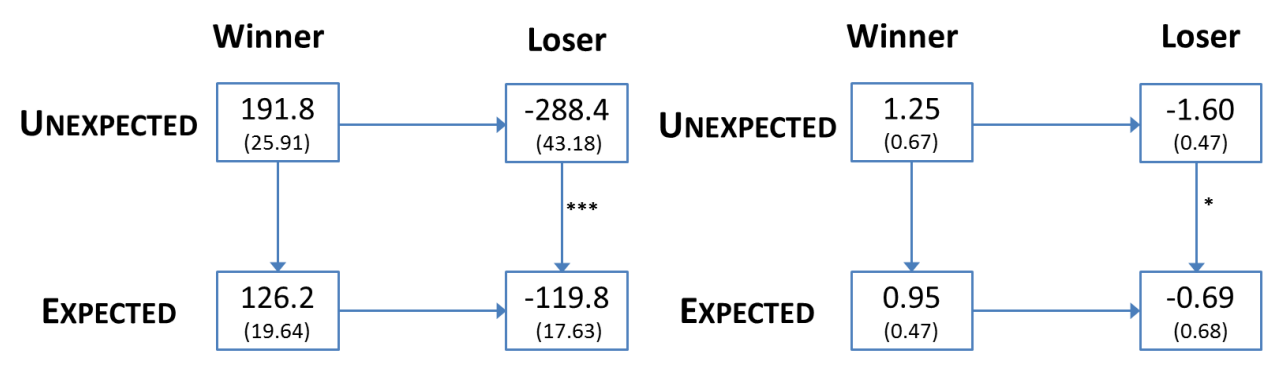

Figure 2: Bid difference (in panel a) and change in satisfaction (in panel b) for winners and losers, separated for unexpected victories (and losses) and expected victories (and losses).

Note: Standard errors in parentheses. 24 gains are classified as unexpected (with the rest of 28 gains as expected) and 20 losses are classified as unexpected (with the rest of 32 as expected).

changes in satisfaction are magnified when the outcome comes as a surprise. Therefore, figure 2 analyzes a specific subset of players for which winning (or losing) either comes as a surprise or is taken for granted, after both players have chosen their efforts and the winning probabilities are revealed. We assume that the subjects whose winning probability is smaller than one third expect to lose and that for these subjects winning comes as a surprise. On the other hand, the subjects with a winning probability larger than two thirds expect to win and for these subjects losing comes as a surprise. ${ }^{15}$ The left panel of figure 2 depicts over- and underbidding for playing the contest again. We find that the magnitude of the joy of winning and of the frustration of losing is larger when winning or losing comes as a surprise, with the difference for losers being highly statistically significant $(\mathrm{p}$-value $<0.01$, Mann Whitney $\mathrm{U}$ test at the individual level). The right panel shows that unexpected winning or losing also leads to a stronger reaction in self-reported satisfaction, although the difference is only significant for losers ( $\mathrm{p}$-value $=0.06$, tested at the individual level). As expected, the joy of winning is higher the lower the actual win probability of this player.

The different dimensions of the joy of winning might alternatively be investigated by a treatment variation with asymmetric players who differ in terms of their marginal costs of effort. Then, the favorite's win probability is higher ex ante and we might expect that ceteris paribus the favorite has a higher frustra-

\footnotetext{
${ }^{15}$ We get qualitatively the same results if we are working with more extreme probability values, but then the number of observations for the unexpected case drops further.
} 


\begin{tabular}{lcccc}
\hline \hline Correlation coefficient & $\Delta_{i}$ & $\Delta s_{i}$ & $x_{i}^{0}$ & $x_{i, \text { old }}$ \\
Bid difference $\Delta_{i}$ & 1.000 & & & \\
& & & & \\
Change in satisfaction $\Delta s_{i}$ & 0.42 & 1.000 & & \\
Effort in zero prize contest $x_{i}^{0}$ & $(0.00)$ & & & \\
& 0.05 & 0.01 & 1.000 & \\
Effort in former contest $x_{i, \text { old }}$ & 0.06 & $(0.90)$ & & \\
& $(0.51)$ & $(0.03$ & 0.28 & $(0.00)$ \\
& & & & \\
\hline
\end{tabular}

Table 3: Correlation between joy measures and effort.

Note: Spearman correlation coefficients between both joy of winning measures, effort in a zero prize contest and effort in the old contest. P-values in parentheses.

tion from losing than the underdog and the underdog has a higher joy of winning than the favourite. However, we look at the most simple case of players with symmetric cost of effort whose role as favourite or underdog is only determined by their own effort choices.

We have two measures for the joy of winning, the bid difference and the change in self-reported satisfaction. Table 3 shows the Spearman correlation coefficient and the corresponding p-value between both measures. We see that bid differences are significantly positively correlated with the change in satisfaction. ${ }^{16}$ Of course, we are also interested in the relation between our measure and the measure that has been used by other studies: effort in a zero-prize contest. The third row of table 3 shows that there is practically zero correlation between this measure and either of our measures. Yet, as hypothesized in the introduction, the effort in this zero-prize contest is significantly positively correlated with the effort in the first contest against a human contestant (see the fourth row). ${ }^{17}$ This speaks for the conjecture that (some) players just type in the same effort in both, zero-prize contests and valuable-prize contests. Interestingly, our joy of winning measures are uncorrelated with the average effort chosen in the former contest. Separating the data according to winner status, we find that the frustration of losing increases with effort in the former contest. In the next paragraph, we want to further investigate these effort choices.

Figure 3 shows the average effort of players in the first contest against a human contestant (first bar from the left) and in the second contest against a human contestant if there was a restart (second bar from the left). We find that

\footnotetext{
${ }^{16}$ However, if concentrating on the subset of winners or losers, we observe both measures to be significantly correlated only in the case of losers.

${ }^{17}$ In fact, we obtain a significantly positive correlation between effort in any contest of value $\mathrm{V}=500$ and effort in a contest of value $\mathrm{V}=0$.
} 


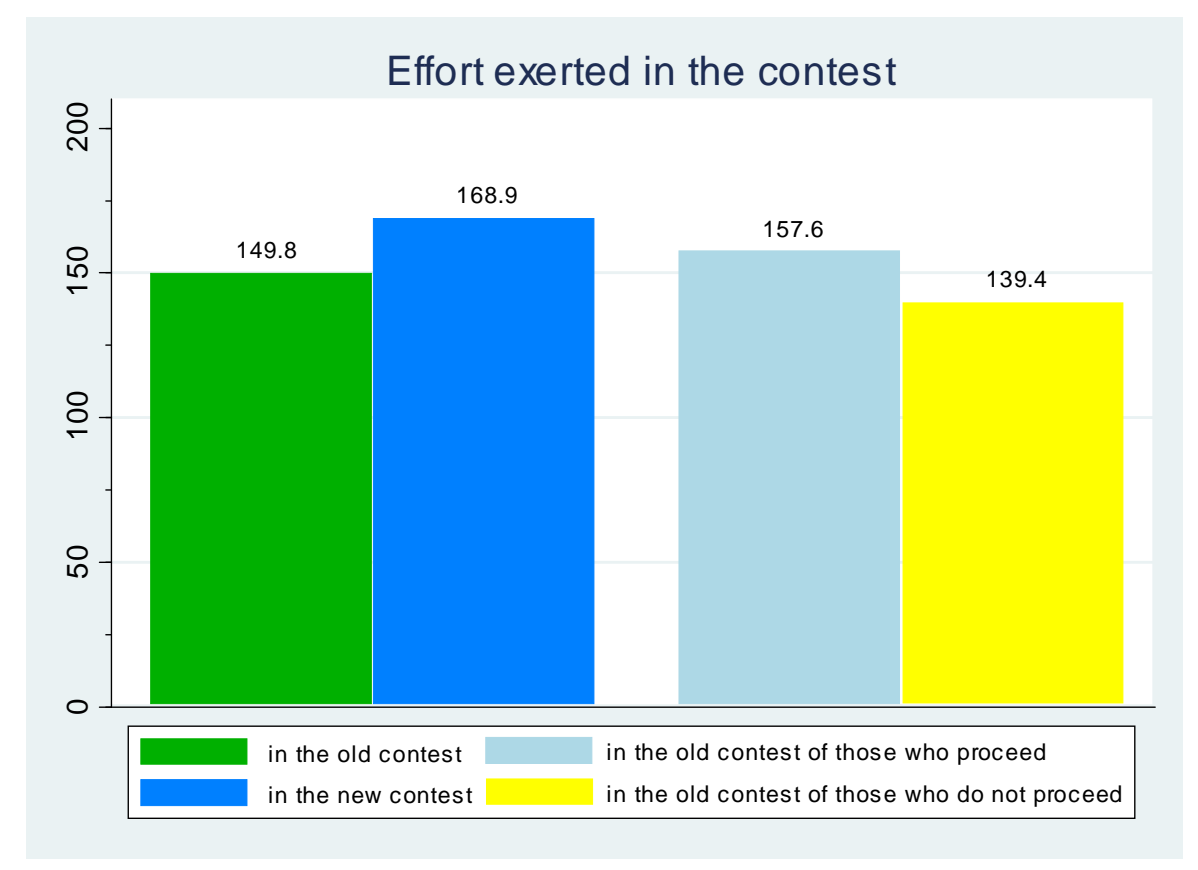

Figure 3: Average effort choices in the contest.

effort in the restarted contest is significantly higher ( $\mathrm{p}$-value $<0.01$, Wilcoxon signed rank test at the matchinggroup level).

Result 4 Average effort in the restarted contest is significantly higher than in the original contest.

The increase could be driven by two different effects: ${ }^{18}$ Either it is due to selection which happens if a specific subset of people who tend to exert a lot of effort enters the second contest more often (because they bid more for replaying the contest). Or the effort increase is a strategic reaction, because players know that they are fighting against a specific subset of people (strategic) or because they have consciously chosen to replay the contest and are now very keen on winning (self-commitment). If the first (selection) effect is true, first contest effort by the players who proceed to play the second contest should be higher than first contest effort by the players who do not proceed to play the second contest. The two bars on the right side of figure 3 show that effort by players who continue is higher on average, but the difference between both types of players is only marginally statistically significant $(\mathrm{p}$-value $=0.11)$. What about the second (strategic) effect? Does the effort level of those players who play both contests differ between the first and second contest? Concentrating on

\footnotetext{
${ }^{18}$ Also see Herbst (2016) for a more formal argument why we expect to see higher effort in the second contest.
} 
the second and third bar in the center of the figure, we see that effort for this subset of players is higher in the second contest and we find this difference to be statistically significant (p-value $=0.03) .{ }^{19}$ Hence, we cannot firmly reject neither of the proposed explanations: The higher effort in the second contest can be explained by both, selection and strategic or commitment effects.

\subsection{Regression analysis}

To further test our predictions we proceed with a multivariate analysis. Table 4 presents the results of three sets of regressions. ${ }^{20}$ In all estimations we control for whether each player was a winner in the previous contest. Moreover, we include socioeconomic information from the post-experimental questionnaire and a number of individual-specific control variables generated in post-experimental tests. All regressions include "effort if $\mathrm{V}=0$ " which is the effort exerted in a zero-prize contest, "risk_general," which is a self-reported measure for the willingness to take risk on an increasing scale from 0 to 10 and "risk_lottery," which measures the number of investments in lotteries with different win probabilities (on a scale from 0 to 5 ). We control for efficiency-searching behavior in individual two-person allocation decisions, for loss aversion, ambiguity aversion, optimism, and pessimism. As socioeconomic variables we further include age, gender, field of study, semester, number of siblings, and the willingness to compete in daily life (deduced from their self-reported participation in a) lotteries, in b) card games and cardboard games, and in c) sports contests or other types of contests).

The dependent variable in columns (1) and (2) is the bid $b_{i}$ that players place for a restart. In line with the non-parametric tests we find that winners place a lower bid than losers. In column (2), "effort $x_{i}$ " also controls for the effort expended in the contest. ${ }^{21}$ We find that keeping the effort level constant, the influence of being a winner continues to be negative. We find that bids only increase by 0.3 points for every unit of effort exerted, although they should increase by 1 point (as independent of being a winner or a loser, the cost of effort in the former contest is completely reimbursed if a restart takes place).

The dependent variable in columns (3) and (4) is our first measure for the joy of winning. Hence, the left-hand side variable in these estimations is overbidding $\Delta_{i}=b_{i}+\pi_{i, \text { old }}-\frac{V}{4}$. We find that overbidding is much higher for winners than for losers, in line with result 1. In column (4), controlling for the effort expended we find the mirror image of column (2): As the observed bids underreact to

\footnotetext{
${ }^{19}$ This result is also in line with a finding by Bradler et al. (forthcoming) according to which recognition increases subsequent performance by the best performers. In our experiment, those subjects with the highest joy of winning are the "best performers" in the first contest, and the opportunity to play it again is some kind of recognition to which they react by increasing their effort levels.

20 Table A.1 in Appendix A.4 repeats estimations (1) to (4) using the full sample as we exclude three outliers in the first four estimations of table 4 . The fit of these regressions deteriorates, but we still that being a winner has a lot of explanatory power.

${ }^{21}$ Effort is closely related to payoff, but we cannot keep payoff constant when changing a subject's status from loser to winner, therefore we decided to include effort.
} 


\begin{tabular}{|c|c|c|c|c|c|c|}
\hline & (1) & $(2)$ & $(3)$ & (4) & $(5)$ & $(6)$ \\
\hline Dep. variable & \multicolumn{2}{|c|}{$\begin{array}{l}\text { bid for restart } \\
b_{i}\end{array}$} & \multicolumn{2}{|c|}{$\begin{array}{l}\text { overbidding } \\
\Delta_{i}\end{array}$} & \multicolumn{2}{|c|}{$\begin{array}{l}\text { change in satisfaction } \\
\Delta s_{i}\end{array}$} \\
\hline constant & $\begin{array}{l}91.6 \\
(66.25)\end{array}$ & $\begin{array}{l}53.8 \\
(70.76)\end{array}$ & $\begin{array}{l}-164.8^{* *} \\
(78.18)\end{array}$ & $\begin{array}{l}-71.1 \\
(70.76)\end{array}$ & $\begin{array}{l}0.55 \\
(1.62)\end{array}$ & $\begin{array}{l}1.71 \\
(1.60)\end{array}$ \\
\hline winner & $\begin{array}{l}-113.7^{* * *} \\
(15.97)\end{array}$ & $\begin{array}{l}-131.1^{* * *} \\
(16.77)\end{array}$ & $\begin{array}{l}325.9^{* * *} \\
(18.62)\end{array}$ & $\begin{array}{l}368.9^{* * *} \\
(16.78)\end{array}$ & $\begin{array}{l}2.33^{* * *} \\
(0.47)\end{array}$ & $\begin{array}{l}2.82^{* * *} \\
(0.55)\end{array}$ \\
\hline effort $x_{i}$ & & $\begin{array}{l}0.29 * * \\
(0.12)\end{array}$ & & $\begin{array}{l}-0.71^{* * * *} \\
(0.12)\end{array}$ & & $\begin{array}{l}-0.01^{* *} \\
(0.003)\end{array}$ \\
\hline effort if $V=0$ & $\begin{array}{l}0.01 \\
(0.13)\end{array}$ & $\begin{array}{l}-0.03 \\
(0.12)\end{array}$ & $\begin{array}{l}-0.13 \\
(0.13)\end{array}$ & $\begin{array}{l}-.0 .03 \\
(0.12)\end{array}$ & $\begin{array}{l}-0.001 \\
(0.004)\end{array}$ & $\begin{array}{l}0.000 \\
(0.004)\end{array}$ \\
\hline risk_general & $\begin{array}{l}-3.94 \\
(5.18)\end{array}$ & $\begin{array}{l}-5.83 \\
(4.85)\end{array}$ & $\begin{array}{l}-10.5^{* *} \\
(4.78)\end{array}$ & $\begin{array}{l}-5.83 \\
(4.85)\end{array}$ & $\begin{array}{l}0.08 \\
(0.15)\end{array}$ & $\begin{array}{l}0.14 \\
(0.15)\end{array}$ \\
\hline risk_lottery & $\begin{array}{l}27.1^{* * *} \\
(8.09)\end{array}$ & $\begin{array}{l}28.9^{* * *} \\
(8.42)\end{array}$ & $\begin{array}{l}33.5^{* * *} \\
(11.38)\end{array}$ & $\begin{array}{l}28.9^{* * *} \\
(8.42)\end{array}$ & $\begin{array}{l}-0.13 \\
(0.32)\end{array}$ & $\begin{array}{l}-0.16 \\
(0.33)\end{array}$ \\
\hline Socioeconomics & yes & yes & yes & yes & yes & yes \\
\hline $\begin{array}{l}\text { Obs } \\
\mathrm{R}^{2}\end{array}$ & $\begin{array}{l}101 \\
0.469\end{array}$ & $\begin{array}{l}101 \\
0.502\end{array}$ & $\begin{array}{l}101 \\
0.832\end{array}$ & $\begin{array}{l}101 \\
0.880\end{array}$ & $\begin{array}{l}104 \\
0.288\end{array}$ & $\begin{array}{l}104 \\
0.322\end{array}$ \\
\hline
\end{tabular}

Table 4: Estimation results.

Note: Standard errors in parentheses, clustered at the individual level. Estimations (1) to (4) exclude three outliers who indicated in the post-experimental questionnaire that they had severe difficulties in understanding the bidding mechanism. 
effort, our overbidding measure is lower the higher effort is. Moreover, in all four regressions we find that bids or bid differences increase with "risk_lottery". This measures the number of times a player invests in lotteries with different exogenous win probabilities in the post-test, and thus measures some kind of risk loving together with being a control for the joy of playing a lottery. None of the other individual-specific characteristics that we obtained from our various posttests and the questionnaire has explanatory power for any of our joy of winning measures. This also implies that loss aversion - which is one of the proposed explanations for overexpenditure in contests - cannot explain the results on bid differences for winners and losers in our framework.

In columns (5) and (6) the dependent variable is our second measure for the joy of winning, i.e. the change in self-reported satisfaction that is induced by playing the first contest against a human contestant. We find that the change in satisfaction is significantly more positive for winners than for losers, in line with result 2. Standard theory predicts that the ones with the highest payoff (winners) should exhibit the highest satisfaction. Therefore, as controlling for payoff directly would already pick up whether someone is a winner or a loser, we control for individual effort in column (6). With every unit of effort expended (controlling for being a winner or loser), the increase in satisfaction is 0.01 units smaller, i.e. player's satisfaction also depends on monetary outcomes. We do not think that monetary payoff is the only explanatory variable for satisfaction differences. Before, we have seen that the reactions to winning or losing are stronger in the restarted contest, although the monetary consequences are almost the same. Yet, if we wanted to change the status of a winner (to a loser) while keeping the payoff constant, we would need to run a further treatment in which losers earn 500 tokens and winners earn, e.g. 1000 tokens. Using this setup, we could check whether the satisfaction increase from gaining $500-x$ tokens differs between winners and losers.

\subsection{Discussion}

We have presented evidence that winning in an experimental contest has additional consequences on top of the allocative ones: Winners are more satisfied than losers and when asked how much they are willing to pay in order to play again, they bid more than a theory model without such non-monetary utility effects would predict. In this section we want to shortly present other explanations that might exist for our observations.

The hot hand bias, a phenomenon first discussed by Gilovich et al. (1985), ${ }^{22}$ suggests that winners believe to win with a higher likelihood when playing again. Therefore, they would overbid and losers would underbid. The gambler's fallacy, according to which random sequences exhibit systematic reversals, suggests that winning players believe to lose the next time. Therefore, they would underbid and losers overbid. Our data are more in line with the hot hand bias. Usually,

\footnotetext{
${ }^{22}$ See also Croson and Sundali (2005) who present evidence for a small bias in this direction and Rabin and Vayanos (2010) for a modeling approach.
} 
this behavioral bias is applied to stochastic events, whereas in our case the players can influence their winning probability by choosing their effort levels and randomness is therefore reduced. Yet, as discussed above, we cannot determine whether differences in the expected payoff of a new contest come from different subjective valuations of the prize or different subjective probability evaluations.

Another caveat is that bids for a restart by both winners and losers exhibit some tendency towards zero. Thus, the results we obtain on the differences in bids (compared to the expected value of a restart) could at least also partly be explained "by construction". However, our data on the satisfaction measure for the joy of winning and the frustration of losing should be unaffected by any of the above mentioned biases (the hot hand, gambler's fallacy, and reversion to zero). Satisfaction differences confirm our results for the incentivized measure, but they can be explained by monetary considerations.

Another line of argument includes relative standing or status considerations, that is, players are better off in terms of utility when they are ahead of the other player. However, note that winning players in our experiment would then not have an incentive to overbid for playing the contest again, as there is some probability of giving up the pole position in the next contest. In even starker contrast stands the behavior of losing players who should bid a lot for their chance of obtaining the pole position in the next contest if they are driven by relative standing considerations, but this is not what we observe.

An interesting treatment variation would be to analyze a proportional prize contest instead of a winner-takes-all contest. This alternative rule has also received attention in the literature. In such a contest, one pays out shares of the prize according to players' win probabilities. By paying out shares, expected payoffs stay the same, but realized payoffs change. In such an environment, we expect to see less of a joy of a winning or a frustration of losing if players always receive that part of the prize that they have a claim on by their winning probability. ${ }^{23}$ Another treatment variation where we predict a null-result concerns the finding on visually tight outcomes. Here, an interesting placebo test would be to eliminate the arrow on the fortune wheel. Then, players do not take one outcome as tight and another one as sure anymore. On the other hand, we would expect all of our results to be stronger if winning is recognized even further by either giving out a nice certificate or publicly announcing victory.

\section{Conclusion}

Among the established results of human behavior in experimental lottery contests is the fact that players typically overexert effort and that effort levels are very heterogeneous across individuals. A common explanation is that there are heterogeneous perceptions of the prize value because for some players winning

\footnotetext{
${ }^{23}$ A similar prediction arises if we were to use a combination of an egalitarian sharing rule with a usual Tullock lottery contest. With this rule (see Nitzan 1991) player's own influence on winning is decreased and this might have an effect on the joy of winning and the frustration of losing.
} 
in itself is worth a lot, while others only care about the monetary value of the prize. With our experiment we aimed at providing evidence for the existence of such an individual-specific joy of winning in experimental contests. We do so by letting players bid for a restart of the contest, which eliminates the monetary payoffs from the former contest. We think that this paper should be welcome to all experimental economists who work on contests and who claim that the joy of winning and its counterpart, the frustration of losing, can explain part of their data.

We find that players who have just won a contest bid much more than the monetary value of a restart for playing the contest again. Furthermore, players who have just lost a contest bid much less than the monetary value of a restart for playing the contest again. We interpret this as evidence for the joy of winning and the frustration of losing. A second, non-incentivized measure confirms our findings: Self-reported emotional states on happiness or satisfaction increase for winners, but decrease for losers.

Effort in a zero-prize contest, a value that has been used to measure the joy of winning in the literature, is not correlated with our incentivized measure nor with our non-incentivized measure. Thus, this measure should be interpreted with caution. We have investigated differences in both of our measures a bit further and find that the effects are larger if the outcome comes unexpected and if it is illustrated as a tight outcome.

On average, effort in the restarted contest is higher than in the original contest. This is due to selection of high effort types, but also because these types increase their effort level even further after selecting into the contest a second time. The higher effort level also has implications for overall efficiency of the contest. Because of the higher level of effort expended, players who select into the restarted contest are on average worse off (in terms of payoff). They might be happy about winning the contest for the first time, but the happiness does not translate into their pockets.

\section{References}

[1] Adam, Marc T. P., Matthias Gamer, Jan Krämer, and Christof Weinhardt, 2011a, Measuring Emotions in Electronic Markets. Proceedings of the International Conference on Information Systems (ICIS). (Shanghai, China). Association for Information Systems. ISBN 978-0-615-55907-0. 1-19.

[2] Adam, Marc T.P., Jan Krämer, Caroline Jähnig, Stefan Seifert, and Christof Weinhardt, 2011b, Understanding auction fever: a framework for emotional bidding, Electronic Markets 21(3), 197-207.

[3] Adam, Marc T. P., Jan Krämer, and Marius B. Müller, 2015, Auction Fever! How time pressure and social competition affect bidders' arousal and bids in retail auctions, Journal of Retailing 91(3), 468-485. 
[4] Astor, Philipp, Marc Adam, Caroline Jähnig, and Stefan Seifert, 2013, The joy of winning and the frustration of losing: a psychophysiological analysis of emotions in first-price sealed-bid auctions, Journal of Neuroscience, Psychology, and Economics 6(1), 14-30.

[5] Balafoutas, Loukas, Rudolf Kerschbamer and Matthias Sutter, 2012, Distributional preferences and competitive behavior, Journal of Economic Behavior \& Organization 83(1), 125-135.

[6] Bartling, Björn, Ernst Fehr, Michel André Maréchal and Daniel Schunk, 2009, Egalitarianism and competitiveness, American Economic Review Papers and Proceedings 99(2), 93-98.

[7] Baumeister, Roy F., Ellen Bratslavsky, Catrin Finkenauer, and Kathleen D. Vohs, 2001, Bad is Stronger than Good, Review of General Psychology $5(4), 323-370$.

[8] Bosman, Ronald, Roman Kräussl, and Thomas van Galen, 2014, Emotionsat-Risk: An Experimental Investigation into Emotions, Option Prices and Risk Perception, LSF Research Working Paper Series No 14-11.

[9] Bradler, Christiane, Robert Dur, Susanne Neckermann and Arjan Non, Employee recognition and performance: a field experiment, Management Science, http://dx.doi.org/10.1287/mnsc.2015.2291, forthcoming.

[10] Brandts, Jordi, Arno Riedl, and Frans van Winden, 2009, Competitive rivalry, social disposition, and subjective well-being: An experiment, Journal of Public Economics 93, 1158-1167.

[11] Brookins, Philip, and Dmitry Ryvkin, 2014, An experimental study of bidding in contests of incomplete information, Experimental Economics 17, 245-261.

[12] Bühren, Christoph, and Marco Pleßner, 2014, The Trophy Effect, Journal of Behavioral Decision Making 27(4), 363-377.

[13] Buser, Thomas, The impact of losing in a competition on the willingness to accept further challenges, Management Science, http://dx.doi.org/10.1287/mnsc.2015.2321, forthcoming.

[14] Cason, Timothy, William A. Masters, and Roman Sheremeta, 2013, Winner-take-all and proportional-prize-contests: Theory and experimental evidence, Working Paper (SSRN-id2345664).

[15] Chen, Yan and John O. Ledyard, 2008, "Mechanism design experiments." in The New Palgrave Dictionary of Economics, Second Edition. Eds. Steven N. Durlauf and Lawrence E. Blume. Palgrave Macmillan.

[16] Coffey, Bentley, and M. T. Maloney, 2010, The thrill of victory: Measuring the incentive to win, Journal of Labor Economics 28(1), 87-112. 
[17] Cotton, Christopher, Cheng Li, Frank McIntyre, and Joseph Price, 2015, Which explanations for gender differences in competition are consistent with a simple game theoretic model?, Journal of Behavioral and Experimental Economics 59, 56-67.

[18] Croson, Rachel, and James Sundali, 2005, The gambler's fallacy and the hot hand: Empirical data from casinos, The journal of risk and uncertainty 30(3), 195-209.

[19] Ding, Min, Jehoshua Eliashberg, Joel Huber, and Ritesh Saini, 2005, Emotional Bidders-An Analytical and Experimental Examination of Consumers' Behavior in a Priceline-Like Reverse Auction, Management Science 51(3), 352-364.

[20] Dohmen, Thomas, Armin Falk, Klaus Fliessbach, Uwe Sunde, and Bernd Weber, 2011a, Relative versus absolut income joy of winning, and gender: brain imaging evidence, Journal of Public Economics 95, 279-295.

[21] Dohmen, Thomas, Armin Falk, David Huffman, Uwe Sunde, Jürgen Schupp and Gert G. Wagner, 2011b, Individual risk attitudes: Measurement, determinants, and behavioral consequences, Journal of the European Economic Association 9(3), 522-550.

[22] Fischbacher, Urs, 2007, Z-tree: Zurich tool box for ready-made economic experiments, Experimental Economics 10(2), 171-178.

[23] Franken, Robert E., and Douglas J. Brown, 1995, Why do people like competition? Motivation for winning, putting forth effort, improving one's performance, performing well, being instrumental, and expressing forceful/aggressive behavior, Personality and individual differences 19(2), 175184.

[24] Fukuda, Emiko, Yoshio Kamijo, Ai Takeuchi, Michiharu Masui, and Yukihiko Funaki 2013, Theoretical and experimental investigations of the performance of keyword auction mechanisms, RAND Journal of Economics 44(3), 438-461.

[25] Gauriot, Romain, and Lionel Page, 2016, Does success breed success? A quasi-experiment on strategic momentum in dynamic contests, Qube Working Paper No. 28, http://www.uq.edu.au/economics/PHD2015/papers/

Gauriot_Does\%20success\%20breed\%20success_a\%20quasi\%20experiment \%20on\%20strategic\%20momentum\%20in\%20dynamic\%20contests.pdf

[26] Gilovich, Thomas, Robert Vallone, and Amos Tversky, 1985, The hot hand in basketball: On the misperception of random sequences, Cognitive Psychology 17, 295-314.

[27] Greiner, Ben, 2004. An Online Recruitment System for Economic Experiments. In: Kurt Kremer, Volker Macho (eds.): Forschung und wissenschaftliches Rechnen 2003. GWDG Bericht 63, Göttingen: Ges. für Wiss. Datenverarbeitung, 79-93 
[28] Haran, Uriel, and Ilana Ritov, 2014, Know who you're up against: Counterpart identifiability enhances competitive behavior, Journal of Experimental Social Psychology 54, 115-121.

[29] Hart, Einav, Judith Avrahami, Yaakov Kareev, and Peter M. Todd, Investing Even in Uneven Contests: Effects of Asymmetry on Investment in Contests, Journal of Behavioral Decision Making 28(4), 395-409.

[30] Herbst, Luisa, 2016, On the selection of happy winners, mimeo.

[31] Herbst, Luisa, Kai A. Konrad, and Florian Morath, 2015, Endogenous group formation in experimental contests, European Economic Review 74, $163-189$.

[32] Johnson, David, and Timothy C. Salmon, 2016, Sabotage versus Discouragement: Which Dominates Post Promotion Tournament Behavior?, Southern Economic Journal 82(3), 673-696.

[33] Kasumovic, Michael M., and Jeffrey H. Kuznekoff, 2015, Insights into Sexism: male Status and Performance Moderates Female-Directed Hostile and Amicable Behaviour, PLoS ONE 10(7), doi:10.1371/journal.pone.0131613.

[34] Kidd, Michael, Aaron Nicholas, and Birendra Rai, 2013, Tournament outcomes and prosocial behavior, Journal of Economic Psychology 39, 387-401.

[35] Kleine, Marco, Pascal Langenbach, and Lilia Zhurakovska, 2016, Fairness and Persuasion: How Stakeholder Communication Affects Impartial Decision Making, Economics Letters 141, 173-176.

[36] Kräkel, Matthias, 2008, Emotions in tournaments, Journal of Economic Behavior \& Organization 67, 204-214.

[37] Lang, Harald, and Florian Morath, 2015, A glance into the tunnel: Experimental evidence on income comparisons under uncertainty, Max Planck Institute for Tax Law and Public Finance Working Paper 201513,http://dx.doi.org/10.2139/ssrn.2703756.

[38] Mago, Shakun, Roman Sheremeta, and Andrew Yates, 2013, Best-of-three contests: Strategic versus psychological momentum, International Journal of Industrial Organization 31, 287-296.

[39] Malhotra, Deepak, 2010, The desire to win: The effects of competitive arousal on motivation and behavior, Organizational Behavior and Human Decision Processes 111, 139-146.

[40] Malhotra, Deepak, Gillian Ku, and J. Keith Murnighan, 2008, When winning is everything, Harvard Business Review May 2008, 78-86. 
[41] Matsumoto, David, and Bob Willingham, 2006, The Thrill of Victory and the Agony of Defeat: Spontaneous Expressions of Medal Winners of the 2004 Athens Olympic Games, Journal of Personality and Social Psychology 91(3), 568-581.

[42] Mellers, Barbara A., Allan Schwartz, Katty Ho, and Ilana Ritov, 1997, Decision affect theory: Emotional reactions to the outcomes of risky options, Psychological Science 8(6), 423-429.

[43] Metzger, Lars P., 2015, Alliance formation in contests with incomplete information, Ruhr Economic Papers No. 544, http://dx.doi.org/10.4419/86788622.

[44] Morgan, John, Henrik Orzen, Martin Sefton, and Dana Sisak, Strategic and Natural Risk in Entrepreneurship: An Experimental Study, Journal of Economics \& Management Strategy, http://dx.doi.org/10.1111/jems.12140, forthcoming.

[45] Nitzan, Shmuel, Collective Rent Dissipation, The Economic Journal 101(409), 1522-1534.

[46] Perez-Truglia, Ricardo, 2016, Journal of Economic Psychology 49, 74-83.

[47] Price, Curtis R., and Roman M. Sheremeta, 2011, Endowment effects in contests, Economics Letters 111, 217-219.

[48] Price, Curtis R., and Roman M. Sheremeta, 2015, Endowment origin, demographic effects and individual preferences in contests, Journal of Economics and Management Strategy 24, 597-619.

[49] Rabin, Matthew and Dimitri Vayanos, 2010, The gambler's and hot hand fallacies: Theory and applications, Review of Economic Studies 77, 730778.

[50] Sheremeta, Roman M., 2010, Experimental comparison of multi-stage and one-stage contests, Games and Economic Behavior 68, 731-747.

[51] Sheremeta, Roman M., 2015, Impulsive Behavior in Competition: Testing Theories of Overbidding in Rent-Seeking Contests, Working Paper, http://papers.ssrn.com/abstract $=2676419$.

\section{A Appendix}

\section{A.1 Fortune wheel}



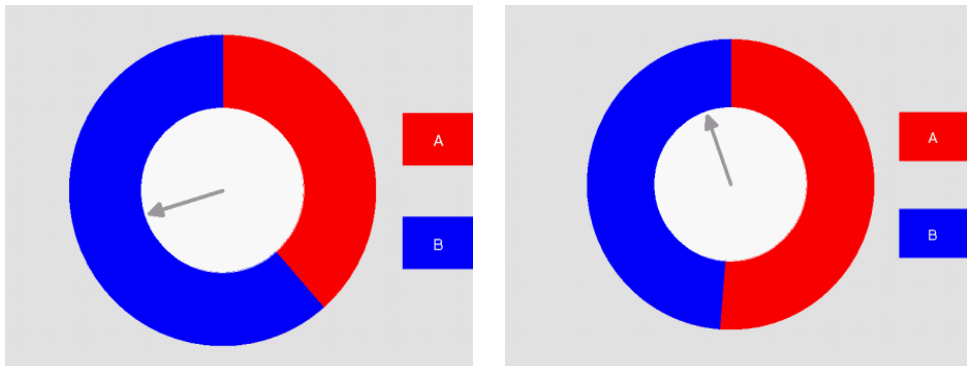

Figure A.1: Screenshots of fortune wheels.

Note: Depicted are two fortune wheels. The red part illustrates the winning probability of player A and the blue part illustrates the winning probability of player B. The arrow starts at the top, moves around and stops randomly. In both illustrations, player B wins. On the left hand side, the outcome seems to be a sure one as the arrow stops far away from a border, whereas on the right hand side, the outcome seems to be a tight one as the arrow stops close to a border.

\section{A.2 Distribution of bids}

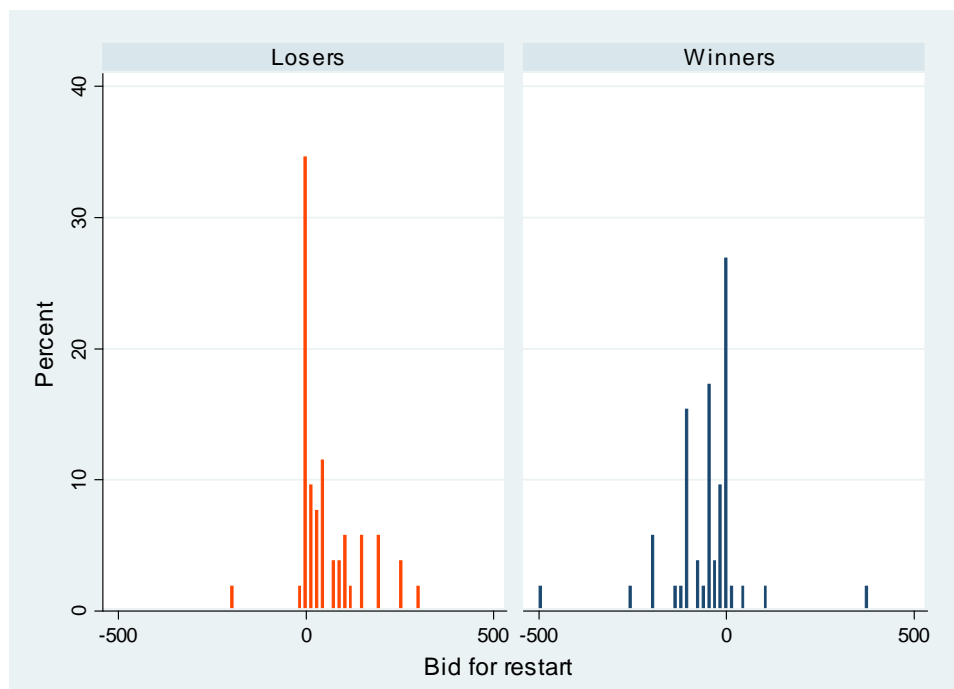

Histogram of the bids for a restart, separated for winners and losers. 


\section{A.3 Distribution of overbidding}

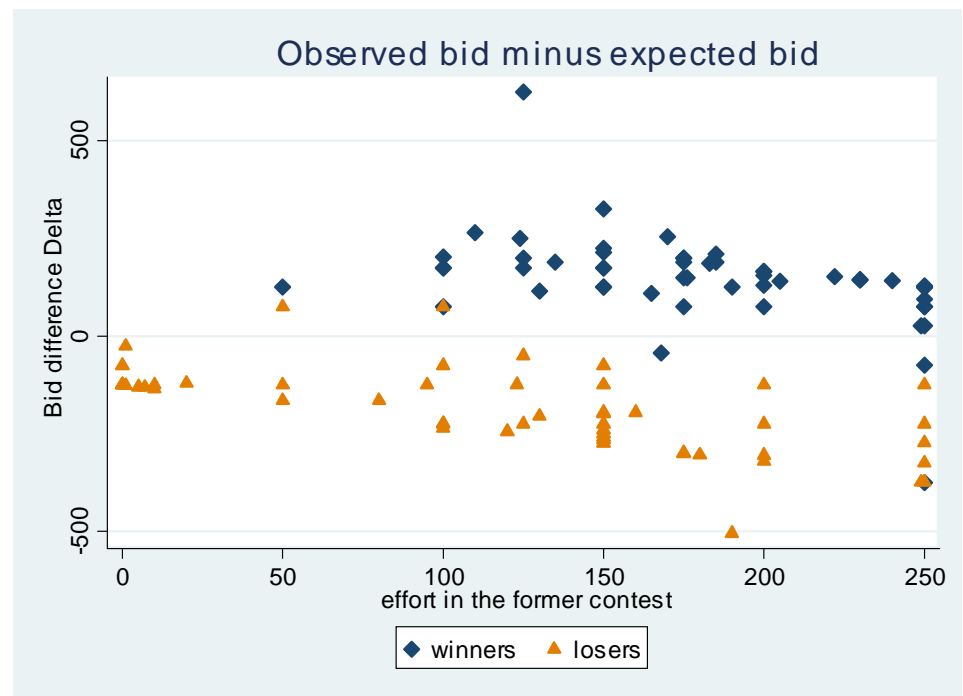

Bid differences for winners and losers.

\section{A.4 Robustness of regressions}

\section{A.5 Instructions ${ }^{24}$}

Welcome to this experiment! Please read the following instructions carefully and entirely. A precise understanding of the instructions can help you to gain more money.

Occasionally you might need to wait for the progress of the experiment. We kindly ask you not to eat, read or use your mobile phone during the experiment. Anything that distracts your attention from the experiment is prohibited. Please note that you are by no means allowed to communicate with other participants. If you violate any of these rules, you will be immediately excluded from the experiment without receiving any payment. If you have any questions please raise your hand. We will be happy to help you.

The experiment consists of several consecutive parts. Your decisions in one part do not impact any other part. In each part you can earn tokens with 50 tokens being equal one euro.

\section{Part 1}

What is it about? Your task is to count the digit zero in a numerical sequence. If your input is incorrect, you can enter your answer again. As soon as you have

\footnotetext{
${ }^{24}$ This section contains a translation of the instructions handed out at the beginning of the experiment.
} 


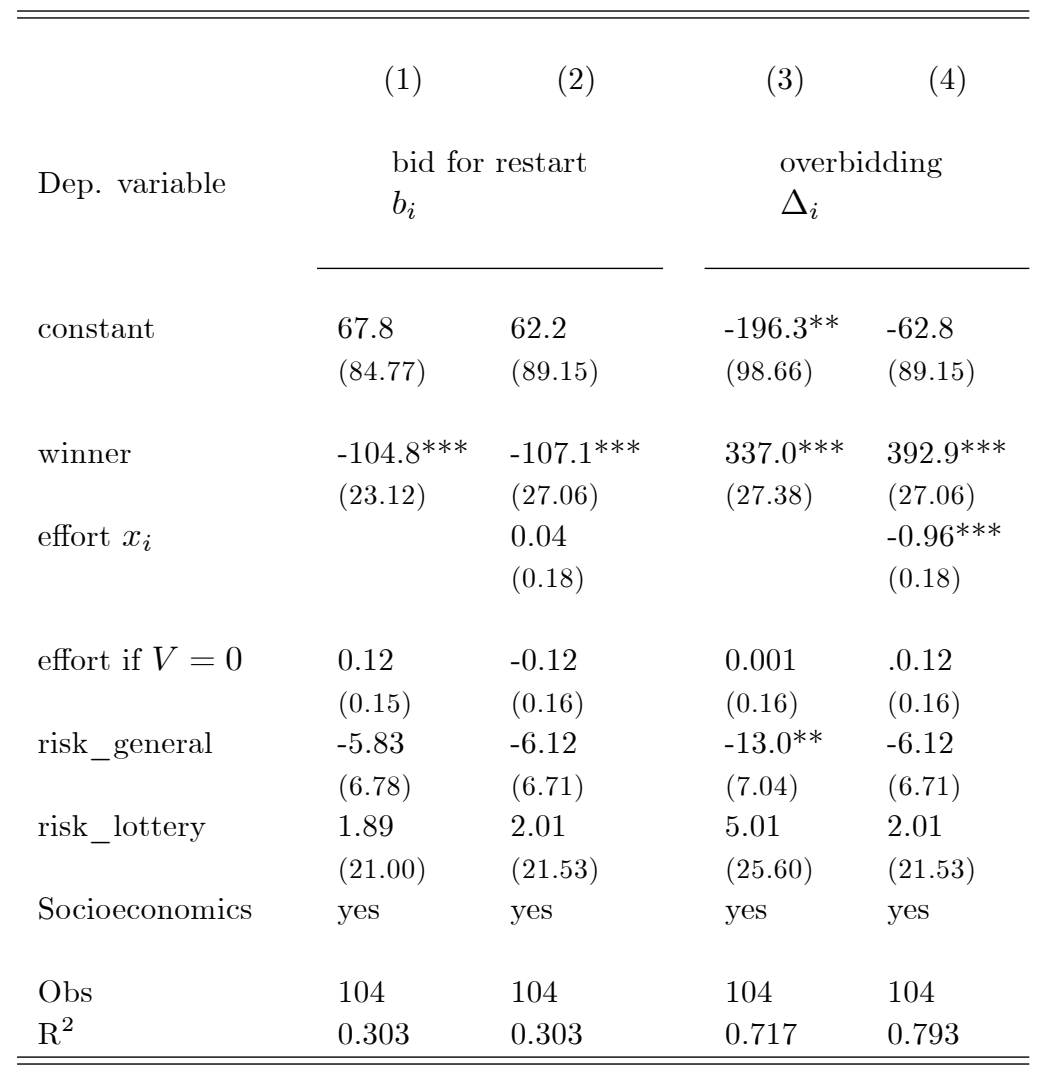

Table A.1: Estimation results.

Note: Standard errors in parentheses, clustered at the individual level.

The table reproduces estimations (1) to (4) of table 4 including all observations.

entered the correct number of zeros, new numerical sequences will be generated.

How many rounds are there? This task will be repeated 15 times. Thus, you have to answer 15 numerical sequences correctly.

What do I earn in part 1? In this part you earn 750 tokens, independent of the number of tries you need. Your earnings serve as your endowment for part 2.

\section{Part 2}

What is it about? After having successfully completed part 1, part 2 will start. In each round of the second part, two participants choose their "investment" simultaneously and independently. The two participants' investments influence their 
probability to receive 500 tokens for themselves in part 2. Every participant can choose any amount between 0 and 250 tokens as investment. The amount entered has to be paid to the laboratory.

How does one round proceed? After both participants have chosen their investment, they will see both investments on the screen. The investments affect which of the two participants will receive the 500 tokens. One participant's probability of success, i.e. the probability that this participant receives the 500 tokens, corresponds to the proportion in his invested tokens on the total amount of tokens invested by him and the other participant. The following applies:

$$
\text { Success probability }=\frac{\text { own investment }}{\text { own investment }+ \text { the other participant's investment }} .
$$

Therefore, the participant who invests more will not automatically receive the 500 tokens. The more tokens a participant invests, however, the more likely he will receive the 500 tokens. Obviously, he then has to pay more tokens to the laboratory. If in one round both participants decide to invest 0 tokens, the probability of success for both participants will be $50 \%$.

The probabilities of success will be shown on the screen as a pie chart, which is divided into two colors. The division arises proportionally out of the two participants' invested tokens. A pointer will rotate slowly on the circular area and randomly stop at one point of the circle. The greater one participant's probability of success, the bigger is his area within the circle and the more likely the pointer will stop in his area. Hence, depending on the area in which the pointer stops, participant 1 or 2 will receive the 500 tokens.

How many rounds are there? The procedure described above under part 2 will be repeated several times. During rounds 1-4, the investment of your co-player will be generated automatically by the computer. This investment of the co-player corresponds to the typical behavior of other participants in the past. The first four rounds will not be paid out. They will help you, however, to gather some experience within the decision-making situation in part 2. After that you will play against another participant of this experiment. For that, the computer will randomly form groups of two. You will not know who your paired participant is.

What do I earn in part 2? Only one round will be paid out in part 2. With your decisions you affect which round will be paid. If you win in the round that is relevant for your payment, you will gain 500 tokens minus your investment in tokens. If instead your player wins, you will have to pay your investment and you will not receive any further payment. That means that you have to pay your investment regardless of receiving the 500 tokens or not.

Part 3 Information about part 3 will appear on the screen at the appropriate time. In this part, all of the participants run through the same 11 scenarios, from which one relevant for payment. 
Summary At the end of today's experiment, your revenues from all parts of the experiment are added up and converted into euros. In addition, you will receive a show-up fee of 6 euros. In any case the total amount of euros will be positive. You will receive your money in cash from the laboratory.

What else should I consider? Before the experiment starts, questions about the process of the experiment are going to appear on the screen. These questions clarify the rules of the experiment by means of examples. Furthermore, we will ask you for some more information during the experiment as well as afterwards; of course all your information is used anonymously. If there is a health-related or technical emergency during the experiment, please press the F1 button.

Thank you for your appearance. Good luck for the experiment! 